\title{
Comparative Anatomical Studies on the Thyroid and Thymic Arteries. V. House musk shrew (Suncus murinus)
}

\author{
By
}

\author{
Masahiro YAMASAKI
}

Department of Anatomy, Akita University School of Medicine, 1-1 Hondo, Akita, Japan

- Received for Publication, January 9, 1997 -

Key Words: Anatomy, Artery, Thyroid gland, Thymus, Suncus

\begin{abstract}
Summary: The thyroid and thymic arteries were investigated in 36 male and 36 female house musk shrews. The superior thyroid artery was constant. The artery arose, in the most instances, from the external carotid and common carotid arteries. The artery, in about one fourth instances, sent both the superior and inferior branches supplying the gland and the former branch terminated in the superior and inferior laryngeal arteries. The latter branch was independent in the remaining instances. The superior laryngeal artery was independent in a few specimens. In some instances, the superior thyroid artery did not send the inferior laryngeal which was the terminal branch of the tracheo-esophageal artery arising mainly from the subclavian and costocervical trunk. The middle thyroid artery was rare only appearing in one male specimen. The inferior thyroid and the thyroid ima arteries were absent in both sexes. On the other hand, the independent thyroid arteries arising from the external carotid, occipital, common carotid and internal carotid arteries appeared in high frequency ( $89 \%$ per body side in an average) in that order of frequency. Most of them may be some separated component of the superior thyroid artery. The middle thymothyroid artery was absent.

The inferior thymic artery arising from the costocervical trunk or the internal thoracic $(49 \%$ in an average) and the middle thymic artery arising from the subclavian $(52 \%)$ shared the arteries supplying the intra-thoracic thymus. The supreme thymic and the superior thymic arteries were very rare, occurring in only one specimen, respectively.

These results show that both the thyroid and thymic arteries in house musk shrews are very simple and seemingly basic, although there are some features characteristic only to this animal.
\end{abstract}

The significance and purposes of this series of studies were mentioned in the previous papers. The present author investigated the thyroid and thymic arteries at the same time systematically in rats (Yamasaki, 1990), Polyprotodont marsupials (1993), guinea pigs (1995) and rabbits (1996) to compare the results each other and with those in man (Yamasaki, 1989b). On the other hand, it is well known that the insectivores are the most primitive eutherians locating just after the marsupials taxonomically. Therefore, it may be valuable to study the arteries of both organs on some member of the order Insectivora. However, although there are some papers dealing with the development of the thyroid gland and thymus in some insectivores (Soulié and Verdun, 1897, on moles; Schaffer, 1909, on moles and shrews; Rabl, 1909 , on moles) and with the anatomy of the Suncus murinus, osteology, myology, middle ear and eye, (Sharma, 1958), the work on the arteries of both organs has not been present as far as the present author knows. Moreover, the descriptions on their arteries in some papers (Versari, 1897; Livini, 1900, both on hedgehogs) and in only monograph (Tanaka et al., 1985 on house musk shrews) are too brief. In the fifth study of this series, the arteries of both organs of house musk shrews were investigated. This animal has been domesticated in Japan (Kondo, 1985) and are now easy to obtain in large quantities at a time. The results obtained will be discussed in comparing with those in other animal species and group already investigated by the present author.

\section{Materials and Methods}

Thirty-six male and 36 female house musk shrews supplied by Dr. Oda were used. They were consisted of eight strains as follows: Nem:NAG originating from Nagasaki, Japan, Nem:TR originating from Taramajima, Okinawa, Japan, Nem:KAT originating from Kathmandu. Nepal, JIc:SUN (via the Chubu Kagaku Shizai Co. Ltd) and Nem:NJ both originating from hybrid lines among NAG, OKI (animals from Okinawa, Japan) and animals in Jawa, Indonesia, Nem:MI originating from hybrid lines between NJ and TR, Nem:SN originating from hybrid lines between NAG and SRI (animals from Sri 
Lanka) and Nem:SK originating from hybrid lines between $N A G$ and $K A T$. The animals were ranging from 3 week old to the fully grown period.

Thirty living (15 males and 15 females) JIC:SUN strain animals were sacrificed in a chamber filled with chloroform vapor. The remaining animals were thawed before use. All of them were injected in a cranial direction with red lead oxide suspended in water through the abdominal aorta. After the thorax was opened and the sternohyoid and sternothyroid muscles were cut at their origins and insertions to exposure the thyroid gland and its arteries, the thyroid and thymic arteries were traced with the aid of a dissecting microscope and figures were drawn for every specimen. All specimens were investigated in an unfixed condition.

The protocols for animal experimentation described in this paper were previously approved by the Animal Research Committee, Akita University School of Medicine; The "Guidelines for Animal Experimentation" of the University were completely adhered to in all subsequent animal experiments.

\section{Results}

In the following descriptions, the Nomina Anatomica (N.A.) will be used in place of the Nomina Anatomica Veterinaria, to more easily compare the present results with those in man.

Although there were some inter-strain differences, they will not be mentioned and discussed because specimen number in some strains, excepting the JIc:SUN, was too small. Following results based on whole specimens as a species.

Because there is no report showing the arteries of the neck region in house musk shrews (only "suncuses" in the following descriptions) as a new laboratory animal, an example is shown in Figure 1 in detail. In the other text-figures, however, some side branches supplying the larynx, salivary glands and muscles and even some glandular rami for the thyroid gland are cut out to avoid the complication of the figures.

\section{Morphology of the Thyroid Gland and Thymus}

The thyroid gland consisted of the paired lobes alongside the caudal part of the thyroid cartilage and the cranial some tracheal cartilages. They had a cranial round body tapering into a slender tail from which a lobule corresponding to the pyramidal lobe reflected cranio-ventrally. Although the isthmus was observed in nine, only male, specimens, it is not shown in all textfigures.

The bilobular thymus was fundamentally intra-thoracic, covering the ventro-lateral surface of the pericardium and the bases of the large vessels. The cranial top of the triangulated thymic lobe did not extend into the cervical region beyond the clavicula and there was no isolated thymic lobule excepting in one male and two female specimens. In the former, there were two slender thymic lobules between the thyroid gland and the main part of the thymus (Fig. 5R. R indicates the right side of the body, $L$ the left and $B$ both sides). In one of the female cases, there was a connective tissue chord bridging two organs (Fig. 3R). The thymus was functional in the adult specimens. The thyroid gland and thymus are dislocated laterally and caudo-laterally respectively in almost all text-figures to show their arteries clearly.

\section{Arteries Supplying the Thyroid Gland}

The superior thyroid artery (Table 1-2) was constant. The artery arose, in the most instances, from the external carotid (Fig. 2R) and from the common carotid artery just caudal to its bifurcation (Fig. 2L). In two male specimens, one on the right and the other on the left side, the artery arose from the common carotid very caudally (Fig. 3R). The artery rounded the cranial margin of the gland to be the descending ramus passing the space between the gland and trachea. During its course the artery sent some glandular rami and superior and inferior laryngeal arteries. In five instances the artery did not send any glandular ramus to be the independent superior laryngeal artery, although it sent also the inferior laryngeal (Table 1-1, Fig. 3L) excepting one case. In this case, the inferior laryngeal artery and some glandular rami, on the right side, were supplied by the branch arising from the descending ramus to be the middle thyroid artery (Yamasaki, 1995) (Table 1-3, Fig. 4R). In four male and five female specimens the artery did not send the inferior laryngeal, which was the terminal branch of the tracheoesophageal artery arising from the subclavian artery in six (Fig. 6B) and the costocervical trunk in three instances. In about one fourth specimens the artery sent an inferior branch which sent some glandular rami to disappear behind the gland supplying the scalenus muscles shown in a small solid circle (Fig. 5R). In two male specimens among them, not the main artery but only the inferior branch sent a glandular ramus (Fig. 5L).

The inferior thyroid, thyroid ima and the middle thymothyroid (Olivier, 1932) arteries were absent in both sexes (Table 1-4, 5,7). On the contrary, there were many independent thyroid arteries (Table 1-6). They arose from the external carotid cranially (Fig. 2L) or caudally to the superior thyroid artery (Fig. 2R), common carotid (Fig. 3L), occipital (Fig. 6R) and from the internal carotid (Fig. 6L) arteries, in that order of frequency. The arteries in question of the second and third groups terminated in the scalenus muscular rami as the inferior branch mentioned above.

In spite of its origin, the artery was double or triple in some specimens (Figs. 1B, 4L). 

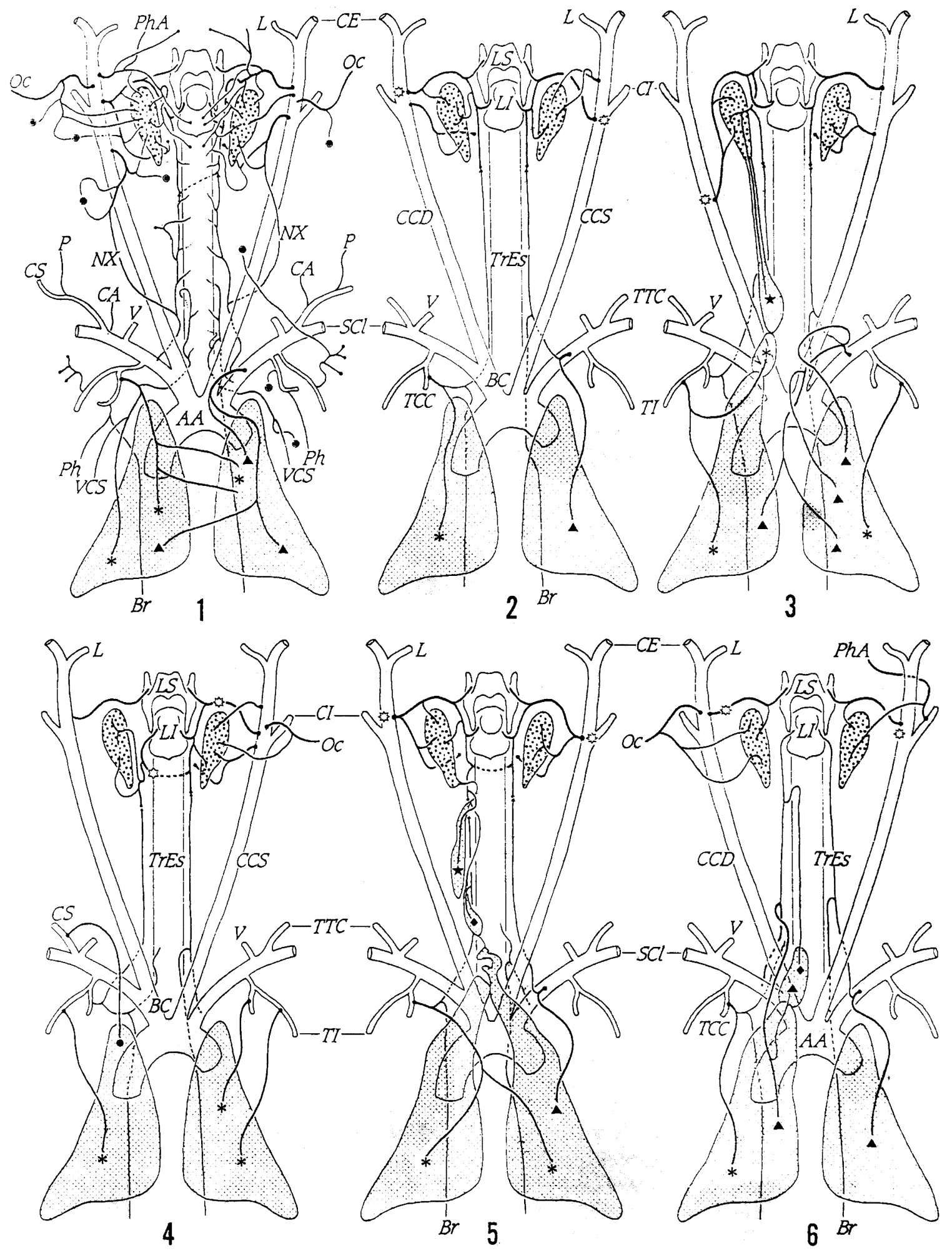

Fig. 1. An illustration showing the arterial system of the neck region.

Figs. 2-6. Semischimatic and montaged drawings of the thyroid and thymic arteries, covering almost all variations of the arteries observed in all specimens. Figure 2 shows the commonest pattern.

$A A$, aortic arch; $B C$, brachiocephalic trunk; $B r$, bronchial artery; $C A$, ascending cervical artery; $C C D, C C S$, right and left common carotid arteries; $C E, C I$, external and internal carotid arteries; $C S$, superficial cervical artery; $L$, lingual artery; $L I, L S$, inferior and superior laryngeal arteries; $N X$, branch accompanying with the vagal nerve; $O c$, occipital artery; $\mathrm{P}$, parotid artery; $P h$, artery accompanying with the phrenic nerve; $P h A$; ascending pharyngeal artery; $S C l$, subclavian artery; $T C C$, costocervical trunk; TI, internal thoracic artery; $\operatorname{TrEs}$, tracheoesophageal artery; $T T C$, thyrocervical trunk; $\mathrm{V}$, vertebral artery; $V C S$, artery accompanying with the superior caval vein.

$\left.\xi_{\xi}\right\}$, superior thyroid artery; $\hat{s}$, middle thyroid artery; $\star$, supreme thymic artery; $\boldsymbol{\bullet}$, superior thymic artery; $\boldsymbol{\Delta}$, middle thymic artery: $*$, inferior thymic artery; $\bullet$, unknown thymic artery; $\odot$, lymph node; $\rightarrow$, muscular branch. 
Table 1. Frequencies of various arteries supplying the thyroid gland and thymus

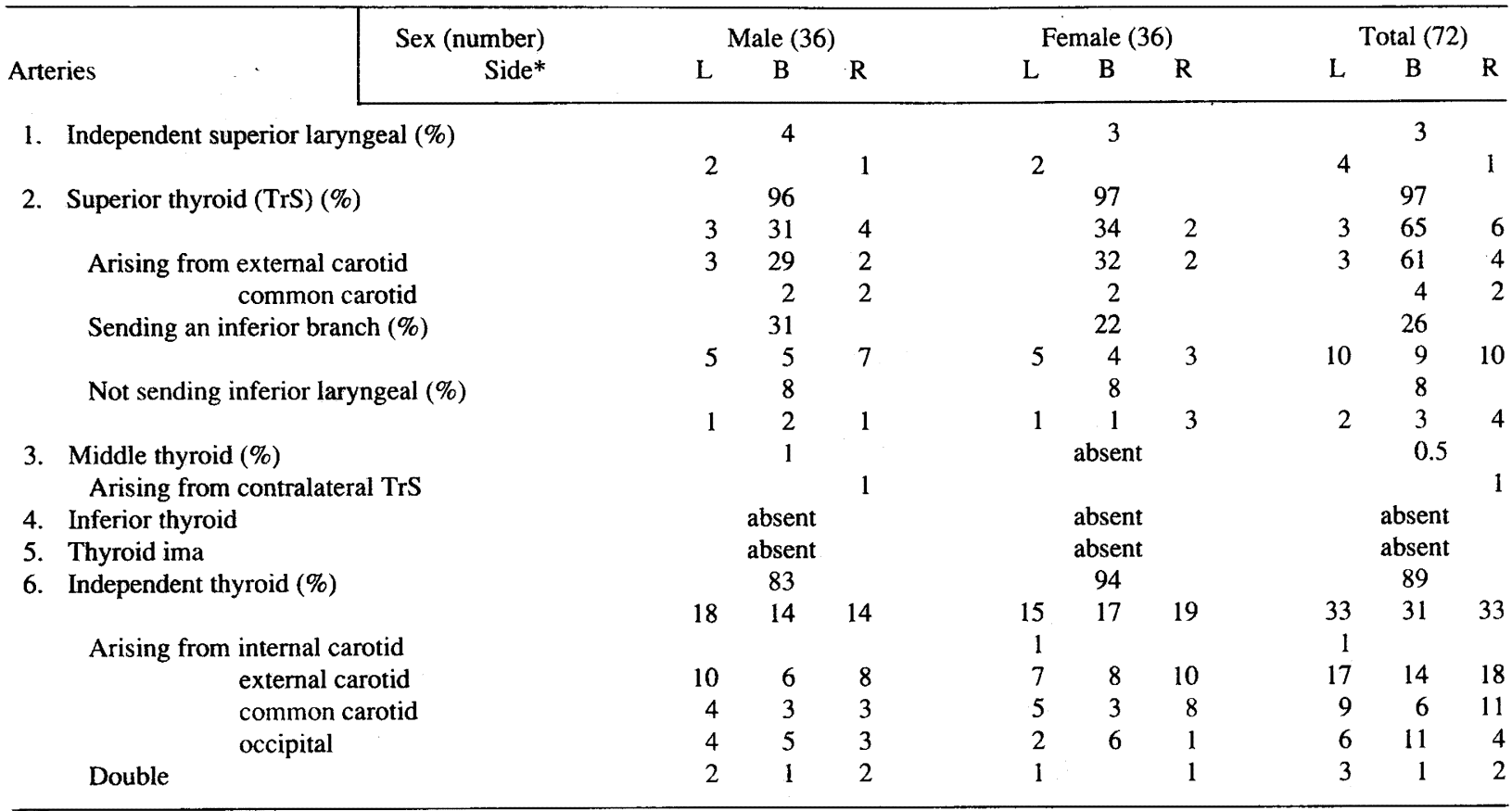

\begin{tabular}{|c|c|c|c|c|c|c|c|c|c|c|}
\hline 7. & Middle thymothyroid & \multicolumn{3}{|c|}{ absent } & \multicolumn{3}{|c|}{ absent } & \multicolumn{3}{|c|}{ absent } \\
\hline 8. & Supreme thymic $(\%)$ & \multicolumn{3}{|c|}{1} & \multicolumn{3}{|c|}{1} & \multicolumn{3}{|c|}{1} \\
\hline & & & & 1 & & & 1 & & & 2 \\
\hline & Superior thymic (\%) & \multicolumn{3}{|c|}{1} & \multicolumn{3}{|c|}{ absent } & \multicolumn{3}{|c|}{0.5} \\
\hline & & & & 1 & & & & & & 1 \\
\hline 10. & Middle thymic (\%) & \multicolumn{3}{|c|}{47} & \multicolumn{3}{|c|}{60} & \multicolumn{3}{|c|}{52} \\
\hline & Arising from subclavian & 17 & 8 & 1 & 20 & 10 & 1 & 37 & 18 & 2 \\
\hline & Supplying both lobes & 2 & & & 7 & & & 9 & & \\
\hline 11. & Inferior thymic $(\%)$ & \multicolumn{3}{|c|}{54} & \multicolumn{3}{|c|}{44} & \multicolumn{3}{|c|}{49} \\
\hline & & 5 & 8 & 18 & 4 & 3 & 22 & 9 & 11 & 40 \\
\hline & Arising from internal thoracic & 3 & & 3 & 1 & & 6 & 4 & & 9 \\
\hline & costocervical trunk & 2 & 8 & 15 & 3 & 3 & 16 & 5 & 11 & 31 \\
\hline & Supplying both lobes & & & & 1 & 1 & 5 & 1 & 1 & 5 \\
\hline
\end{tabular}

${ }^{*} \mathrm{~L}$, left; $\mathrm{R}$, right; $\mathrm{B}$, both sides.

\section{Arteries Supplying the Thymus}

The middle thymic (Table 1-10) and inferior thymic arteries (Table 1-11) both of Versari (1897) were almost equal in frequency. Most of the latter artery arose from the costocervical trunk (Fig. 2R), which was rarely independent (Fig. 1L), and in the remainining instances directly from the internal thoracic artery (Fig. 2L). Only in one female specimen, two types of the artery coexisted (Fig. 4L). In seven only female specimens (one on the both sides), the artery supplied both lobes (Fig. 5R). This artery occurred twice in males and about four times in females on the right side as frequently as on the left. On the contrary, the middle thymic arteries arising only from the subclavian were about three times, on the left side (Fig. $2 \mathrm{~L}$ ), as much as on the right in both sexes. The artery supplied both lobes in two male and seven female specimens (Fig. 3L). The instance where one middle and one inferior thymic artery coexisted occurred in two male on the left side and two female, one on the right and one on the both sides, specimens (Fig. 3L).

The supreme thymic artery (Yamasaki, 1989a) (Table 1-8) appeared in one male and one female specimen, which arose from the descending branch in the former (Fig. 5R) and from the posterior ramus of the superior thyroid artery to pass the connective tissue chord in the latter instance (Fig. 3R). The superior thyroid artery of Versari (1897) (Table 1-9) arising from the superficial cervical occurred in only one male specimen (Fig. 4R). The thymic artery arising from the tracheo-esophageal artery was observed in one male, in which the supreme thymic artery coexisted (Fig. 5R, $\diamond$ ) and one female instance (Fig. 6R, $\bullet$ ).

The right tracheo-esophageal artery arose overwhelmingly from the costocervical trunk, including some 
instances where it arose from the internal thoracic artery or the brachiocephalic trunk. In about $74 \%$, in an average, of the right tracheo-esophageal arteries made a common trunk with the inferior thymic artery (Fig. 2R). On the other hand, the left tracheo-esophageal arteries arose from the subclavian artery and $62 \%$ of them made a common trunk with the middle thymic artery (Fig. 2L). The tracheo-esophageal artery was double, more cranial of which was main and the more caudal was accessory, in four male and twelve female specimens. The pairs of their origins were composed of two subclavian arteries ( 2 males and 5 females, Fig. 5L), two costocervical trunks ( 1 female, Fig. 4R) and one subclavian and one costocervical ( 2 males and 6 females, Fig. 6R). The tracheo-esophageal artery, on each side, sent caudally a bronchial artery which in some instances arose from the other arteries as shown in Figure 1R.

\section{Discussion}

Versari's (1897) thyro-laryngeal artery in hedgehogs may correspond to the superior thyroid artery in suncuses. Recently Tanaka et al. (1985) described that, in the latter animal, the external carotid artery sends laryngeal, pharyngeal and thyroid arteries. This is not accurate, because the independent superior laryngeal artery was very rare. As shown in Table 2-1, the artery is lowest in frequency among the animal species listed, only followed by man and showing high contrast to rabbits. In contrast with this, the superior thyroid artery was overwhelming (Table 2-2). Yamashita et al. (1985) noted that the thyroid gland, in suncuses, receives the superior thyroid artery arising from the external carotid and its branch. This is correct approximately, because the former artery arose from the common carotid, although in low frequency, and did not arise from any branch of the external carotid. They may put together the independent thyroid arteries arising from the occipital. Localization of the origin of the superior thyroid artery to the external carotid in suncuses is the strongest among the species in Table 2-2. Livini's descriptions (1900) that the thinner superior laryngeal artery in hedgehogs does not arise from the common carotid but from the thicker inferior laryngeal artery are obscure and do not correspond to the situation in suncuses. The superior thyroid artery sending both the superior and inferior laryngeal arteries appears in high frequency in rats and Polyprotodonts (Yamasaki, 1990, 1993) in contrast with in rabbits (ibid, 1996).

Therefore, the extremely low frequency of the middle thyroid artery, which was introduced from the constant superior thyroid artery in suncuses, is prominent among the species in Table 2-3 excepting man. Absence of the inferior thyroid and thyroid ima arteries coincides practically with that in Polyprotodonts, rats and rabbits (Table 2-4, 5). The description of Yamashita et al. (1985) that the thyroid gland in suncuses receives the inferior thyroid artery arising from the common carotid or deep cervical artery is not understandable. They may note the usual inferior thyroid artery, which is the tracheo-esophageal in this report and the previous papers (Yamasaki, 1995, 1996) agreeing with the opinions of Bugge (1967) and Booth and Ghoshal (1977). In rabbits there were many tracheo-esophageal artery arising from the common carotid (Yamasaki, 1995). However, in suncuses, there was no instance where such artery and the inferior thyroid arising from the costocervical trunk, superficial cervical or deep cervical arteries observed in man occurred. Moreover, almost all right tracheo-esophageal artery arose from the costocervical trunk and the left artery from the subclavian. The tracheo-esophageal artery in suncuses was the simplest among the species listed in Table 2.

The highest frequency of the independent thyroid arteries is characteristic to suncuses (Table 2-6). In contrast with guinea pigs and rabbits where these arteries arose from some arteries far from the thyroid gland (Yamasaki, 1995, 1996), almost all of them arose from the vicinity of the gland, as if the gland is situated in an arterial network (Fig. 1B). However, most of them arising from the common carotid, especially caudally to the superior thyroid artery, would be a part or the inferior branch of the latter artery.

Thus, the thyroid artery in suncuses in general is the simplest, followed by Polyprotodonts and rats.

The thymic arteries in suncuses are unique in comparison with those in species in Table 2 excepting guinea pigs. That is; the thymic arteries are shared by the middle and inferior, the latter of which is dominant in other species and the former arose exclusively from the subclavian artery. Although Versari (1897) noted that the thyro-laryngeal artery in hedgehogs does not send any thymic artery, the supreme thymic artery was present in suncuses. However, the extremely low frequency of the supreme and superior thymic artery is hold in common only by Polyprotodonts.

It is supposed that the thymic arteries shift successively cranio-caudally during its descent from the most cranial superior superficial cervical thymic artery arising from the lingual in guinea pigs (Yamasaki, 1995) to the most caudal inferior thymic artery via the supreme thymic (Yamasaki, 1989a), superior thymic and middle thymic arteries (Rogers, 1929-1930; Grobler, 1977; Yamasaki, 1989b). According to this supposition, the thymic arteries in suncuses may be nearly at the final condition, which is almost achieved in Polyprotodonts. In these two animal groups, the thymic arteries are poor in quality in contrast with those in rats, rabbits and man. In the latter three species, therefore, the shift of the thymic artery may be proceeding even after birth or, in 
Table 2. Percentage frequencies per body side of various arteries supplying the thyroid gland and thymus in some eutherian species and a marsupial group

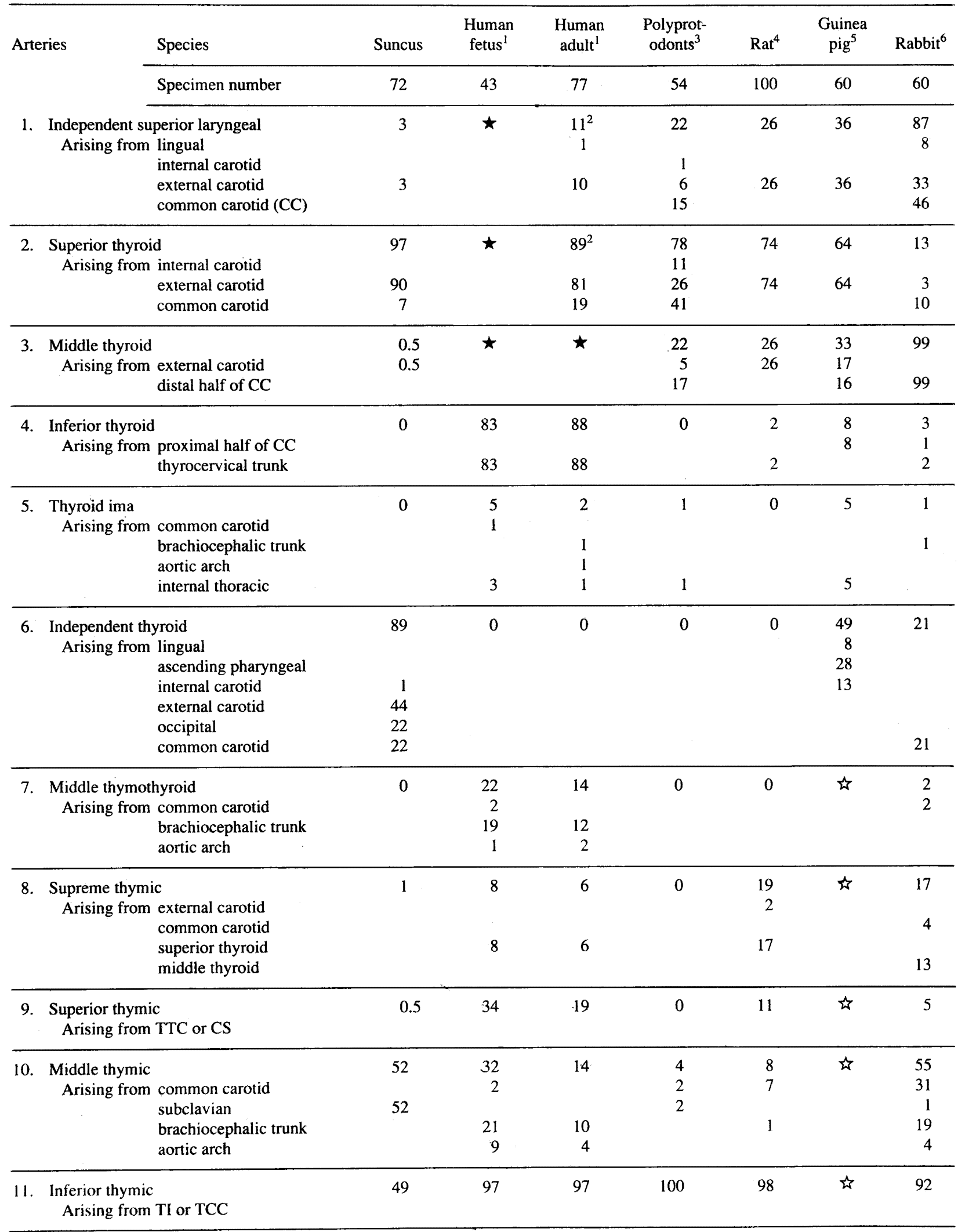

For explanation of abbreviation, see caption to Figures $1-6 . \star$, Data not available; $\{$, data on the superficial cervical thymus are not comparable to the thoracic thymus of other species. Data are based on the results in ${ }^{1}$ Yamasaki (1989b), ${ }^{2}$ Lippart and Pabst (1985), ${ }^{3}$ Yamasaki (1993), ${ }^{4}$ Yamasaki (1990), ${ }^{5}$ Yamasaki (1995) and ${ }^{6}$ Yamasaki (1996). 
other words, thymic arteries are maintaining still some relation with the thyroid gland to be unstable. It is clearly shown in higher frequencies of the middle thymothyroid, thyroid ima and supreme thymic arteries in these three species than in Polyprotodonts and suncuses.

The thymic artery arising from the tracheo-esophageal in two specimens (Figs. 5R, 6R, $\bullet$ ) have not been reported and appeared in the other species in Table 2. The artery does not belong to any thymic artery mentioned above and suggests that the tracheo-esophageal may send the thymic artery. The unknown thymic artery may be forced to be the superior or middle thymic artery according to the level of its origin. However, it may be necessary to rearrange the thymic arteries chiefly based on the Versari's classification (1897), as discussed in guinea pigs and rabbits (Yamasaki, 1995, 1996) where some thymic arteries deviating from his classification.

\section{Acknowledgement}

The author expresses his sincere appreciation and gratitude to Associate Professor Dr Sen-ichi Oda, Laboratory of Animal Management, School of Agricultural Sciences, Nagoya University, for supplying most of the specimens.

This work was supported by a Grant-in-Aid for General Research (C) No. 02670003 from the Japanese Ministry of Education, Science and Culture.

\section{References}

1) Booth $\mathrm{KK}$ and Ghoshal NG. Is there a caudal thyroid artery in the dog (Canisfamiliaris)? Acta Anatomica 1977; 99:183-187.

2) Bugge J. Arterial supply of the cervical viscera in the rabbit. Acta Anatomica 1967; 68:216-227.

3) Grobler NJ. Textbook of clinical anatomy, pp. 89-90. Amsterdam: Elsevier, 1977.

4) Kondo K. Development of new laboratory animals, in Suncus murinus. Biology of the laboratory shrew (in Japanese), chief ed. Kondo, pp. 1-7. Tokyo: Japan Scientific Societies Press, 1985.

5) Lippert $\mathrm{H}$ and Pabst R. Arterial Variations in Man. Classification and Frequency, pp. 83, 84. München: Bergmann, 1985.

6) Livini F. Studio morfologico delle arterie tiroidee. Lo Sperimentale Archivio di Biologia normale e pathologica 1900; 54:42-129.
7) Olivier E. Les rapports des artéres thymiques avec les artères thyroidiennes. Comptes Rendus de l'Association des Anatomistes 1923; 18:413-417.

8) Rabl H. Das thyreo-thymische System des Maulwurfs und der Spitzmaus. Zweiter Teil. Die Entwicklung des thy reo-tymischen Systems beim Maulwurf. Sitzungsberichte der Akademie der Wissenschaften in Wien. Mathematische-Naturwissenschaftliche Klasse. Abt. 3: Anatomie und Physiologie des Menschen und der Tiere 1909; 118:549-628.

9) Rogers L. The thyroid arteries considered in relation to their surgical importance. Journal of Anatomy 1929-1930; 64:5061 .

10) Schaffer J. Das thyreo-thymische System des Maulwurfs und der Spitzmaus, Erster Teil. Abschnitt A. Morphologie und Histologie. Sitzungsberichte der Akademie der Wissenschaften in Wien. Mathematisch-Naturwissenschaftliche Klasse. Abt. 3: Anatomie und Physiologie des Menschen und der Tiere 1909; 117:551-659.

11) Sharma DR. Studies on the anatomy of the Indian insectivore, Suncus murinus. Journal of Morphology 1958; 102:427-553.

12) Soulié A and Verdun P. Sur les premiers développements de la glande thyroïde, du thymus et des glandules satellites de la thyrö̈de chez le lapin et chez la taupe. Journal de l'Anatomie et de la Physiologie Normales et Pathologiques de l'Homme et des Animaux 1897; 33:604-653.

13) Tanaka T, Nishida T, Miyaki T and Hayakawa T. Cardiovascular system of the house musk shrew in Suncus murinus. Biology of the laboratory shrew (in Japanese), chief ed. Kondo, pp. 279285. Tokyo: Japan Scientific Societies Press, 1985.

14) Versari R. Le arterie timiche nell'uomo ed in altri mammiferi. Loro rapporti colle arterie tiroidee. Bolletino della Societa Lancisiana delgi Ospedali di Roma 1897; 17:64-82.

15) Yamasaki $M$. On the A. thymica suprema, a provisionally named branch of the superior thyroid artery in the human. Anatomischer Anzeiger 1989a; 168:329-335.

16) Yamasaki M. Studies on the thyroid and thymic arteries of Japanese adults and fetuses. Anatomischer Anzeiger 1989b; 169:213-221.

17) Yamasaki M. Comparative anatomical studies of thyroid and thymic arteries: I. Rat (Rattus norvegicus albinus). The American Journal of Anatomy 1990; 188:249-259.

18) Yamasaki M. Comparative anatomical studies on the thyroid and thymic arteries, II. Polyprotodont marsupials. Journal of Anatomy 1993; 183:359-366.

19) Yamasaki M. Comparative anatomical studies on the thyroid and thymic arteries, III. Guinea pig (Cavia cobaya). Journal of Anatomy, 1995; 186:383-393.

20) Yamasaki M. Comparative anatomical studies on the thyroid and thymic arteries, IV. Rabbit (Oryctolagus cuniculus). Journal of Anatomy, 1996; 188:557-564.

21) Yamashita K, Fujioka T, Kito J and Sugiura Y. Endocrine organs of the house musk shrew, in Suncus murinus. Biology of the laboratory shrew (in Japanese), chief ed. Kondo, p. 267. Tokyo: Japan Scientific Societies Press, 1985. 